\title{
Cannabinoids for pain management: What is their role?
}

\author{
Alexander J Clark MD FRCPC ${ }^{1}$, Mary E Lynch MD FRCPC ${ }^{2}$
}

In the popular press, many Canadians claim to be using herbal cannabis (marijuana) to control symptoms such as pain, nausea, muscle spasm, anorexia and anxiety that may be associated with diseases like AIDS/HIV, multiple sclerosis, epilepsy and chronic pain. Surveys of patients with chronic pain, multiple sclerosis and epilepsy suggest that approximately $10 \%$ to $12 \%$ of these patients are active cannabis users, and up to $36 \%$ have tried using herbal cannabis or its derivatives to control symptoms they experience with these diseases (1-3).

On the other hand, the prescription cannabinoids available have, to date, only limited use in the management of pain. Neither nabilone (Cesamet, Valeant Canada limitée/Limited) nor dronabinol (Marinol, Solvay Pharma Inc, Canada) have pain as an indication according to the Canadian Compendium of Pharmaceuticals and Specialties (4), while Sativex (GW Pharma Ltd, United Kingdom) is only indicated for neuropathic pain in multiple sclerosis.

Although there is a large and growing preclinical literature regarding potential therapeutic uses of cannabinoids, there are few studies on the clinical efficacy of natural and synthetic cannabinoids as analgesics. Previous available studies have involved only small numbers of subjects and were often of limited quality (5).

An overview of the rapidly developing basic science relevant to potential analgesic actions of cannabinoids (6), which includes a review of the endogenous cannabinoid system; evidence of antinociceptive, antihyperalgesic and anti-inflammatory actions; and a review of the pharmacokinetics of cannabinoids (7) is presented in this special issue. Reviews of the current literature assist in understanding the possible toxic effects (8), safety (9) and risks of addiction (10) of cannabinoids. As with all pharmacologically active agents, currently available cannabinoids are associated with adverse effects, and it is important to be aware of these effects as clinicians begin to consider these agents in the treatment of pain. Examples include effects on drowsiness, attention and cognition, the possibility of exaggerating existing psychoses or provoking others long-term, postural hypotension and tachycardia.
Further understanding the roles of the cannabinoid receptors $\left(\mathrm{CB}_{1}\right.$ and $\left.\mathrm{CB}_{2}\right)$ and the development of new cannabinoid receptor agonists will allow us to maximize the analgesic efficacy and minimize the side effects caused by the cannabinoids. Development of novel agonists, which do not cross the bloodbrain barrier, alternative methods of delivery (ie, transdermal, buccal, rectal, etc), and further elaboration of ways to manipulate the endogenous cannabinoid system are all exciting areas of research that will lead to compounds exhibiting greater efficacy, and potentially fewer adverse effects. However, it will likely be several years before such compounds will be clinically available and, right now, we need to be familiar with the currently available compounds.

The purpose of the present supplement to Pain Research $\mathbb{E}$ Management is to provide Canadian clinicians and researchers with comprehensive reviews of the current basic and clinical science regarding cannabinoids, along with up-to-date reviews of the literature relevant to safety, toxicity and the risk of addiction related to cannabinoids.

The authors of the present supplement have developed an algorithm for use by clinicians in the assessment and treatment of chronic pain when cannabinoid compounds are considered. In addition, guidelines for the use of the two oral cannabinoid compounds that are currently available by prescription in Canada are provided. It is not possible to make recommendations about the buccal administered cannabinoid compound because information is limited.

The use of smoked herbal cannabis should be discouraged; there is significant controversy regarding this route of delivery. There is no question that smoking is toxic, but can patients limit their risk by minimizing the dose? Do the benefits outweigh the risks in some cases? The answers to these questions await further study and, until inexpensive, safer and efficient methods of delivery are available, it is probable that some patients with pain and other symptoms will seek relief by smoking cannabis. Others may receive existing preparations for off-label use.

It is the goal of the present supplement to assist clinicians, researchers and policy makers with these issues.

\footnotetext{
${ }^{1}$ Chronic Pain Centre, Calgary Health Region, and Department of Anesthesia, University of Calgary, Calgary, Alberta; ${ }^{2}$ Pain Management Unit, Queen Elizabeth II Health Sciences Centre, and Departments of Psychiatry and Anesthesia, Dalhousie University, Halifax, Nova Scotia Correspondence and reprints: Dr Alexander J Clark, Chronic Pain Centre, Calgary Health Region, 160-2210 2nd Street SW, Calgary, Alberta T2S 3C3. Telephone 403-943-9900, fax 403-209-2955, e-mail john.clark@calgaryhealthregion.ca
} 
DECLARATION OF INTEREST: This series of articles has been supported by an unrestricted grant from Valeant Canada limitée/Limited. The grant enabled a symposium to be held in Montreal, Quebec on June 4, 2004 and facilitated preparation of the manuscripts. The Editor-in-Chief of the Journal, Dr Harold Merskey, participated in the symposium. The participants and authors wish to acknowledge the support provided.

\section{REFERENCES}

1. Ware MA, Doyle CR, Woods R, Lynch ME, Clark AJ. Cannabis use for chronic non-cancer pain: Results of a prospective survey. Pain 2003;102:211-6.

2. Clark AJ, Ware MA, Yazer E, Murray TJ, Lynch ME. Patterns of cannabis use among patients with multiple sclerosis. Neurology 2004;62:2098-100.

3. Gross DW, Hamm J, Ashworth NL, Quigley D. Marijuana use and epilepsy: Prevalence in patients of a tertiary care epilepsy center. Neurology 2004;62:2095-7.
4. Compendium of Pharmaceuticals and Specialties. Ottawa: Canadian Pharmacists Association, 2005.

5. Ware M, Beaulieu P. Cannabinoids for the treatment of pain: An update on recent clinical trials. Pain Res Manage 2005;10(Suppl A):27A-30A

6. Lynch ME. Preclinical science regarding cannabinoids as analgesics: An overview. Pain Res Manage 2005;10(Suppl A):7A-14A.

7. McGilveray IJ. Pharmacokinetics of the cannabinoids. Pain Res Manage 2005;10(Suppl A):15A-22A.

8. Beaulieu P. Toxic effects of cannabis and cannabinoids: Animal data. Pain Res Manage 2005;10(Suppl A):23A-26A.

9. Ware MA, Tawfik VL. Safety issues concerning the medical use of cannabis and cannabinoids. Pain Res Manage 2005;10(Suppl A):31A-37A.

10. Gourlay D. Addiction and pain medicine. Pain Res Manage 2005;10(Suppl A):38A-43A 


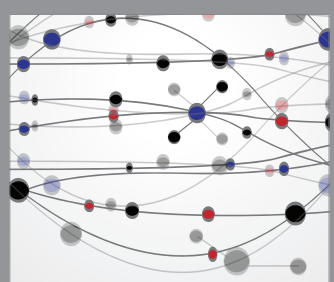

The Scientific World Journal
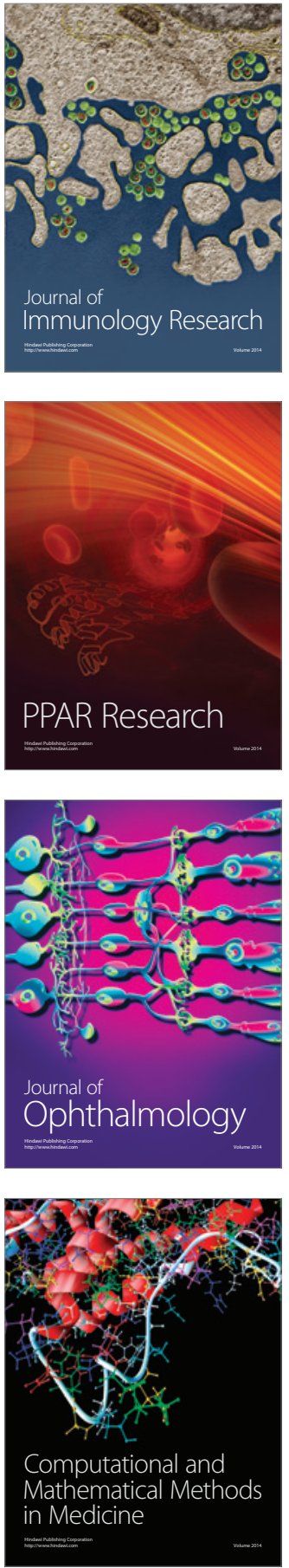

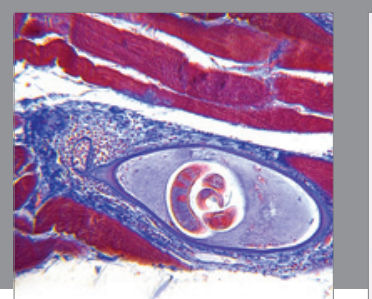

Gastroenterology Research and Practice

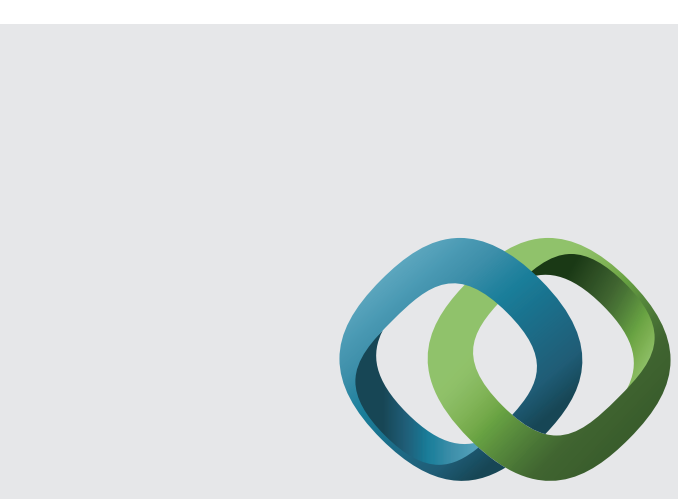

\section{Hindawi}

Submit your manuscripts at

http://www.hindawi.com
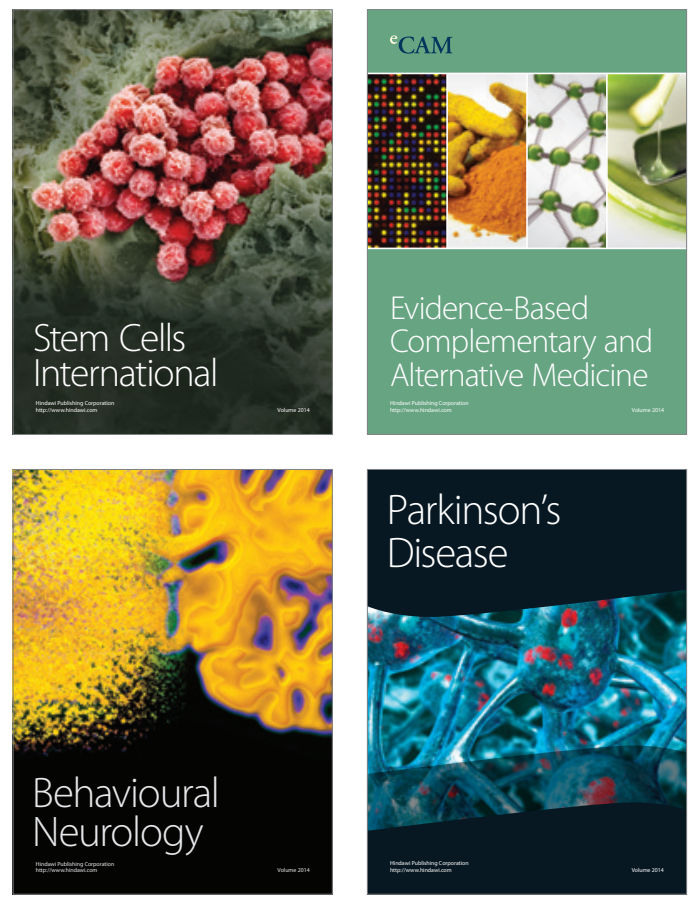
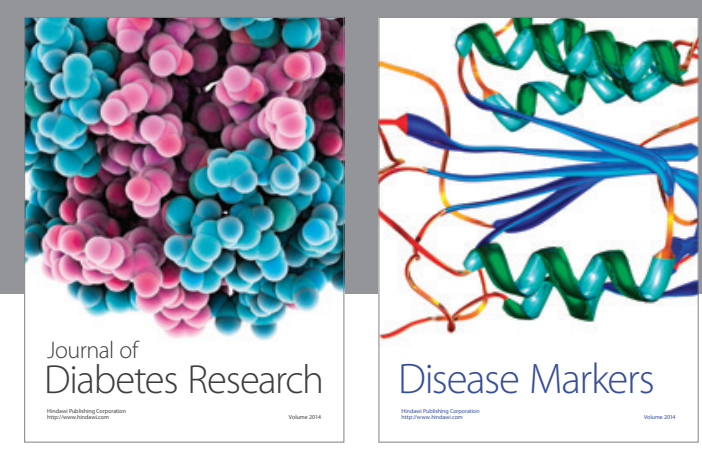

Disease Markers
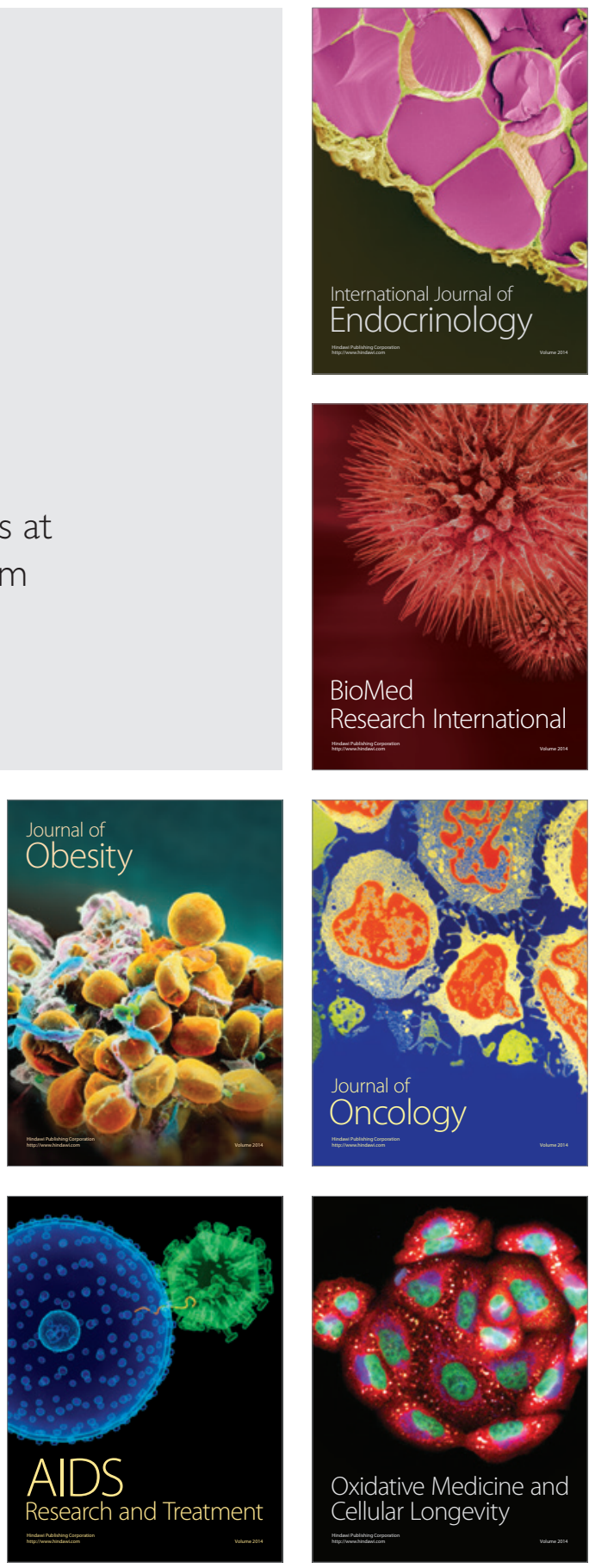